\title{
Platelet concentrate and type II IL-1 receptor are risk factors for allergic transfusion reactions in children
}

\author{
Wenjing $\mathrm{Hu}^{1 \dagger}$, $\mathrm{Li} \mathrm{Feng}^{2+}$, Meng $\mathrm{Li}^{2}$, Ting $\mathrm{Li}^{2}$, Yudong Dai ${ }^{3^{*}}$ and Xiaowei Wang ${ }^{2^{*}}$
}

\begin{abstract}
Purpose: Allergic transfusion reactions (ATRs) are immunological reactions after transfusion. Interleukin-1 (IL-1) is a critical regulator for human diseases. We performed this study to investigate the association of type II IL-1 decoy receptor (IL1R2) expression with ATRs in children.
\end{abstract}

Methods: Children received blood transfusions between January and December 2019 were included. The age, sex, number and type of blood transfusion, allergic history, and medical history were collected and statistically analyzed. The blood samples were collected from children with and without ATRs for detecting the relative expression IL1R2 mRNA. Logistics regression analysis was performed to identify the risk factors for ATRs in children. The area under the receiver operating characteristic (ROC) curve (AUC) was used to evaluate the predictive performance of risk factors.

Results: Totally, 28,840 transfusions in 20,230 children, with 236 ATRs (0.82\%) in 117 patients (0.58\%) were included. ATRs were common in children at the hematology-oncology department, in children received higher number of blood transfusions, and older children. Platelet concentrate induced a higher incidence of ATRs (3.31\%) than red cell concentrate $(0.22 \%, p<0.0001)$. After the transfusion, IL1R2 mRNA level was higher in the blood samples in children with ATRs than those without ATRs ( $p$ < 0.0001). Logistics regression analysis indicated that platelet concentrate $(95 \% \mathrm{Cl} 3.555,293.782)$ and IL1R2 expression $\left(95 \% \mathrm{Cl} 1.171 \times 10^{2}, 1.494 \times 10^{4}\right)$ were independent risk factors for ATRs in children. IL1R2 expression had high performance in predicting ATRs (AUC $=0.998,100 \%$ sensitivity and $98.85 \%$ specificity).

Conclusion: High IL1R2 expression level in children who received blood transfusions may predict the morbidity of ATR.

Keywords: Type II IL-1 decoy receptor, Allergic transfusion reactions, Platelet concentrate, Logistics regression analysis

\section{Highlights}

1. The frequency of allergic transfusion reactions (ATRs) post blood transfusion is $0.82 \%$.

2. Platelet transfusion induced a higher ATRs incidence $(3.31 \%)$ than the $0.22 \%$ of red cells.

* Correspondence: daiyudong7308@126.com; wangxiaowei875@163.com †Wenjing $\mathrm{Hu}$ and Li Feng are the co-first authors.

${ }^{3}$ Nanjing Red Cross Blood Center, \#3 Zizhulin, Nanjing 210003, China

Department of Blood Transfusion, Children's Hospital of Nanjing Medical University, 72 Guangzhou Avenue, Nanjing, Jiangsu 210008, P.R. China

Full list of author information is available at the end of the article
3. Patients with ATRs had a higher level of IL1R2 mRNA than control.

4. IL1R2 expression was an independent risk factor for ATRs in children.

\section{Introduction}

Allergic transfusion reactions (ATRs) are the most common complications of blood transfusions, especially for the platelet transfusion [1]. Platelet has been identified as a risk factor for ATRs [2]. However, the molecular mechanisms underlying ATRs are largely unknown at present. 
ATRs are immunological reactions mediated by the allergen-dependent and -independent pathways [1]. The release of histamine and platelet-activating factor (PAF) are involved in allergen-dependent pathways [1]. Interleukin-1 (IL-1) stimulates PAF production in human vascular endothelial cells [3, 4], and the latter enhances the production of tumor necrosis factor-alpha (TNF- $\alpha$ ) and IL-1 in monocytes [5]. Therefore, PAF may be the major chemical mediator and the biggest culprit of ATRs. What's more, the association of cytokines including IL-6 and IL-8 with ATRs and febrile nonhemolytic transfusion reactions (FNHTR) in pediatric patients had been confirmed [6].

IL-1 polypeptides, including IL- $1 \alpha$ and IL- $1 \beta$, are critical activators and regulators for the pathogenesis of human diseases [7]. There are two types of IL-1 receptors, the type I IL-1 receptor (IL1R1) which is responsible for the transduction of IL-1-dependent intracellular signaling; and the type II IL-1 receptor (IL1R2) that lacks the IL-1 intracellular TIR signal transduction domain, on contrast, serves as a decoy receptor and an inhibitor of IL-1 signaling [7]. IL1R2 may act through hindering and neutralizing the IL-1 signal transduction $[8,9]$. IL1R2 is natively expressed in neutrophils, monocytes, and macrophages, and is inducible in endothelial cells [10]. The expression of IL1R2 has been identified as a potential therapeutic target for several diseases including arteriosclerosis [7, 8]. However, the association of IL1R2 expression with ATRs in children is not clear till now.

We performed this study to investigate the difference in IL1R2 expression in pediatric patients with and without ATRs after transfusion. The potential of using IL1R2 as an independent risk factor for ATRs would be statistically analyzed and discussed. This study may provide more information on the pathogenesis and management of ATRs in children.

\section{Materials and methods Ethical statement}

Ethical approval was obtained from the Ethics Committees of the Children's Hospital of Nanjing Medical University, Nanjing, China. Human experiments were performed strictly according to the revised (2013) Helsinki Declaration of 1975. Written informed consents were obtained from the guardians of all children before the collection of the blood samples.

\section{Subjects and baseline characteristics}

This study included children (aged $\leq 18$ ) who received blood transfusion therapy during January and December 2019 at our hospital. Transfusion products included platelet concentrate ( $\mathrm{PC}, \gamma$ irradiation-treated), suspended leukocyte-reduced red blood cells (SLRBC), fresh-frozen plasma (FFP), and cryoprecipitate. All the blood products were obtained from Nanjing Red Cross Blood Center, Nanjing, China. The baseline characteristics including age, sex, number, and type of transfusion received, history of allergy, and medicine were recorded. All children received premedication before blood transfusion.

\section{FNHTR and ATR definition}

ATRs and related inflammatory symptoms were defined and reviewed by the physicians and/or nurses with reference to the clinical course and medical history of patients. FNHTR was defined as fever (body temperature rose more than $1{ }^{\circ} \mathrm{C}$ within $24 \mathrm{~h}$ ) which may be companied by nausea, rigor, vomiting, skin itching, transient hypertension, and dyspnea without hemolysis and bacterial infection. Acute ATRs were assessed and defined as patients with at least one symptom within the first $4 \mathrm{~h}$ after transfusion, including skin itching, urticaria, rash, fever, rigor, jaundice, cough, dyspnea, bronchospasm, stomachache, headache, conjunctival edema, erythema, edema of the periorbital area, angioedema at the transfusion site, and hypotension [11]. Both FNHTRs and acute ATRs were categorized as ATRs in this study.

\section{Data classification}

The data from pediatric patients were classified and grouped according to age ( $<3$ years, 3-6 years, 6-12 years and $12-18$ years), sex, the number of transfusions received (1, 2-5 times, $6-10$ times and $>11$ times), product type (PC, SLRBC, FFP, and cryoprecipitate), allergic and medical history (food, pollen, rhinitis, and drug), department and ATR types.

\section{Blood collection and real-time RT-PCR analysis}

Venous blood samples were collected into BD PAXgene Blood RNA tube (Becton, Dickinson and Company, NJ, USA) from patients before premedication and after blood transfusion (within $24 \mathrm{~h}$ post transfusion or in the first $24 \mathrm{~h}$ of ATRs). Blood samples were stored at $-20^{\circ} \mathrm{C}$ before RNA extraction. Total RNA was isolated using QIAamp RNA Blood Mini Kits (Qiagen, Nanjing, China) following the protocol from manufacturers. RNA samples were reversely transcribed into the first-strand cDNA and double-strand DNA. The amplification of IL1R2 mRNA was performed using an SYBR Green Master Mix kit (Vazyme, Nanjing, China) and the specific primers (IL1R2 forward: 5' -ACCGCTGTGTCCTG ACATTT - 3' and reverse: 5'-GGAAGAGCGAAACC CACAGA-3'). RT-PCR analysis was conducted according to the reaction conditions: $95^{\circ} \mathrm{C}$ for $4 \mathrm{~min}$; 40 cycles of $95^{\circ} \mathrm{C}$ for $20 \mathrm{~s}, 58^{\circ} \mathrm{C}$ for $30 \mathrm{~s}$ and $72^{\circ} \mathrm{C}$ for $20 \mathrm{~s}$; and $72^{\circ} \mathrm{C}$ for $5 \mathrm{~min}$. The relative expression level of IL1R2 mRNA was calculated using the $2^{-\triangle \Delta C t}$ method. GAPDH was used as the internal reference gene. 


\section{Statistical analysis}

The SPSS 22.0 software was used for the statistical analysis. The frequency of ATRs was presented as proportion and compared using Fisher's exact test. Logistics regression analyses were performed to identify the risk factors for ATRs. Odds ratio (OR) and 95\% confidence interval (CI) were calculated. The relative expression level of IL1R2 mRNA was expressed as the mean \pm standard deviation. The one way ANOVA test (with Tukey test) was used to analyze the difference in the relative expression level of IL1R2 mRNA. The accuracy for predicting ATRs in children was evaluated using the area under the receiver operating characteristic (ROC) curve (AUC). $P<0.05$ was set as the threshold for statistical significance.

\section{Results}

\section{Demographic characteristics}

A total of 28,840 transfusions and 20,230 children were included in this study, with an average number of 1.43 transfusions per child. Two-hundred and thirty-six ATRs $(0.82 \%, 236 / 28840)$ in 117 patients $(0.58 \%, 117 / 20,230)$ were reported. There was no difference in the frequency of ATRs between female and male children $(p=0.514)$, and children with and without a history of allergy ( $p=$ 0.134; Table 1). Children at Hematology-Oncology ward ranked the first in the frequency of ATRs (1.59\%), followed by children in surgical ICU department $(0.88 \%)$. A higher number of blood transfusions and older age significantly increased the risk of ATRs $(p<0.0001)$. In addition, children received PC were at a higher risk of ATRs (3.31\%) compared with patients received SLRBC $(0.22 \%)$, FFP $(0.45 \%)$, and cryoprecipitate $(2.27 \% ; p<$ 0.0001). Urticaria ranked first in the type of ATR (68.64\%), followed by rash (6.78\%), and erythema (6.78\%). Fourteen children had FNHTRs (5.93\%), and 20 children (8.47\%) had the other types of ATRs (including 4 coughs, 2 dyspnea, 1 rigor, 2 stomachaches, 3 laryngeal edema, 2 shocks, 2 emeses, and 4 asymptomatic itches).

\section{The different expression level of IL1R2 in patients with and without ATR}

The blood samples were collected from children before premedication and after blood transfusion, including 66 patients with ATRs (including 6 FNHTRs). The paired blood samples were taken from 66 with ATRs and 500 patients without ATRs before premedication and after blood transfusion, respectively, were used for PCR analysis. In children with ATRs, the relative expression level of IL1R2 was significantly upregulated after blood transfusion versus before ( $p<0.0001$; Fig. $1 \mathrm{~A})$, and was higher than children without ATRs $(p<0.0001)$. No significant changes were observed in the expression level of IL1R2
mRNA in children without ATRs before and after transfusion.

\section{Identification of risk factors for ATR}

Univariate logistics regression analysis showed that PC $(\mathrm{OR}=20.175,95 \%$ CI 10.635, 38.275, $p<0.0001$; Table 2), number of transfusion $(\mathrm{OR}=1.648,95 \% \mathrm{CI} 1.426,1.904$, $p<0.0001)$, age $(\mathrm{OR}=1.076,95 \%$ CI 1.016, 1.139, $p=$ $0.013)$, and IL1R2 expression $\left(\mathrm{OR}=5.574 \times 10^{3}, 95 \% \mathrm{CI}\right.$ $\left.2.569 \times 10^{2}, 5.756 \times 10^{4}, p<0.0001\right)$ were associated with ATRs in children. Multivariate logistics regression analysis indicated that $\mathrm{PC}(\mathrm{OR}=32.318,95 \%$ CI 3.555 , 293.782, $p=0.002)$ and IL1R2 expression $(\mathrm{OR}=1.322 \times$ $10^{3}, 95 \%$ CI $\left.1.171 \times 10^{2}, 1.494 \times 10^{4}, p<0.0001\right)$ were independent risk factors for ATRs (Table 2). After removing the FNHTRs cases $(n=6)$, PC and IL1R2 expression were still the risk factors for ATRs $(p<0.01$, Table S1). The ROC analysis showed that IL1R2 expression (AUC $=0.998,95 \%$ CI $0.996,1.000, \mathrm{p}<0.0001)$ and PC $(\mathrm{AUC}=0.739,95 \%$ CI 0.661, 0.816, $\mathrm{p}<0.0001)$ had high performance for predicting ATRs in children (Fig. 1B). The sensitivity and specificity of IL1R2 expression and PC was $100 \%(95 \%$ CI 93.15, 100\%) and $60.34 \%$ (95\% CI 46.64, 72.68\%), and $98.85 \%$ (95\% CI 97.17, 99.58\%) and 92.99\% (95\% CI 90.09, 95.11\%), respectively.

\section{Discussion}

The association of PC transfusion and cytokines of IL 6 and IL-8 with ATRs has been reported in children [6]. PAF-mediated allergen-dependent pathway during ATRs may play a major role and act as the biggest culprit of the pathogenesis of ATRs [4]. The modulation of IL-1 on PAF or vice versa may provide evidence on IL-1mediated inflammation in ATRs [3-5]. Our present study demonstrated that the expression of IL1R2 mRNA in children with ATRs was elevated post transfusion. We showed that PC transfusion and IL1R2 expression were independent risk factors for ATRs.

PC transfusion has been identified as a leading cause of transfusion reactions [12]. Here in our study, the frequency of ATRs post PC transfusion was $3.31 \%$, and that post SLRBC transfusion was $0.22 \%$. This data was consistent with the reported ATRs frequency of less than $6 \%$ in previous reports $[13,14]$. As expected, PC transfusion was identified as a risk factor for ATRs after transfusion $(95 \%$ CI $3.555,293.782)$. We confirmed that PC transfusion had a high accuracy in predicting ATRs in children with a relatively high specificity and sensitivity. The reduced utilization of PC would decrease the incidence of ATRs.

Poststorage leukoreduction of blood products, including apheresis platelets, significantly increased the production of pro-inflammatory cytokines like IL-1 $\beta$ and IL-8. This fact was associated with the increased 
Table 1 The demographic characteristics of all children

\begin{tabular}{|c|c|c|c|}
\hline Variable & Number of patients/transfusion & Number of ATRs & P \\
\hline Sex & $n=20,230$ & $n=117$ & 0.514 \\
\hline -Female & 9161 & $49(0.53 \%)$ & \\
\hline -Male & 11,069 & $68(0.62 \%)$ & \\
\hline Age & $n=20,230$ & $n=117$ & $<0.0001$ \\
\hline$-<3$ years & 9332 & $18(0.19 \%)$ & \\
\hline$-3-6$ years & 8350 & $55(0.66 \%)$ & \\
\hline$-6-12$ years & 1364 & $29(2.13 \%)$ & \\
\hline$-12-18$ years & 1184 & $15(1.27 \%)$ & \\
\hline Allergic history & $n=20,230$ & $n=117$ & 0.134 \\
\hline -None & 18,395 & $102(0.55 \%)$ & \\
\hline -Drug & 651 & $7(1.08 \%)$ & \\
\hline -Food, Rhinitis, pollen and others & 1184 & $8(0.68 \%)$ & \\
\hline Number of transfusion per patient & $n=20,230$ & $n=117$ & $<0.0001$ \\
\hline-1 & 7816 & $21(0.27 \%)$ & \\
\hline$-2-5$ & 9751 & $56(0.57 \%)$ & \\
\hline$-6-10$ & 2195 & $61(2.78 \%)$ & \\
\hline$->11$ & 468 & $13(2.78 \%)$ & \\
\hline Products & $n=28,840$ & $n=236$ & $<0.0001$ \\
\hline$-P C$ & 4292 & $142(3.31 \%)$ & \\
\hline$-S L R B C$ & 11,571 & $26(0.22 \%)$ & \\
\hline -FFP & 12,801 & $64(0.45 \%)$ & \\
\hline -Cryoprecipitate & 176 & $4(2.27 \%)$ & \\
\hline Department & $n=28,840$ & $n=236$ & $<0.0001$ \\
\hline -Hematology-Oncology & 6814 & $109(1.59 \%)$ & \\
\hline -Surgical ICU & 2162 & 19 (0.88\%) & \\
\hline -Pediatric ICU & 1876 & $5(0.27 \%)$ & \\
\hline -Cardiothoracic surgery & 3139 & $18(0.57 \%)$ & \\
\hline -General surgery & 2697 & $21(0.78 \%)$ & \\
\hline -Outpatient & 9321 & $47(0.50 \%)$ & \\
\hline -Other & 2831 & $17(0.60 \%)$ & \\
\hline ATR type & & $n=236$ & \\
\hline -urticaria & / & $162(68.64 \%)$ & \\
\hline -FNHTR & / & $14(5.93 \%)$ & \\
\hline -rash & / & $16(6.78 \%)$ & \\
\hline -erythema & / & $16(6.78 \%)$ & \\
\hline -skin itching & / & $8(3.39 \%)$ & \\
\hline -Others & / & $20(8.47 \%)$ & \\
\hline
\end{tabular}

ATR allergic transfusion reaction, $P C$ platelet concentrate, SLRBC suspended leukocyte-reduced red blood cells, FFP fresh-frozen plasma, ICU intensive care unit, FNHTR non-hemolytic transfusion reactions

incidence of ATRs to the transfusion of poststorage leukocyte-reduced blood components [15]. Lin et al. also reported the significant increase in the levels of plasma IL-8 and IL-6 in patients had FNHTR [16]. Our present study for the first time reported the significant increase of IL1R2 mRNA in children with ATRs post transfusion. The increased expression level of IL1R2 was an independent risk factor for ATRs in children.

It was previously reported that FNHTRs were associated with the increased levels of human leukocyte 


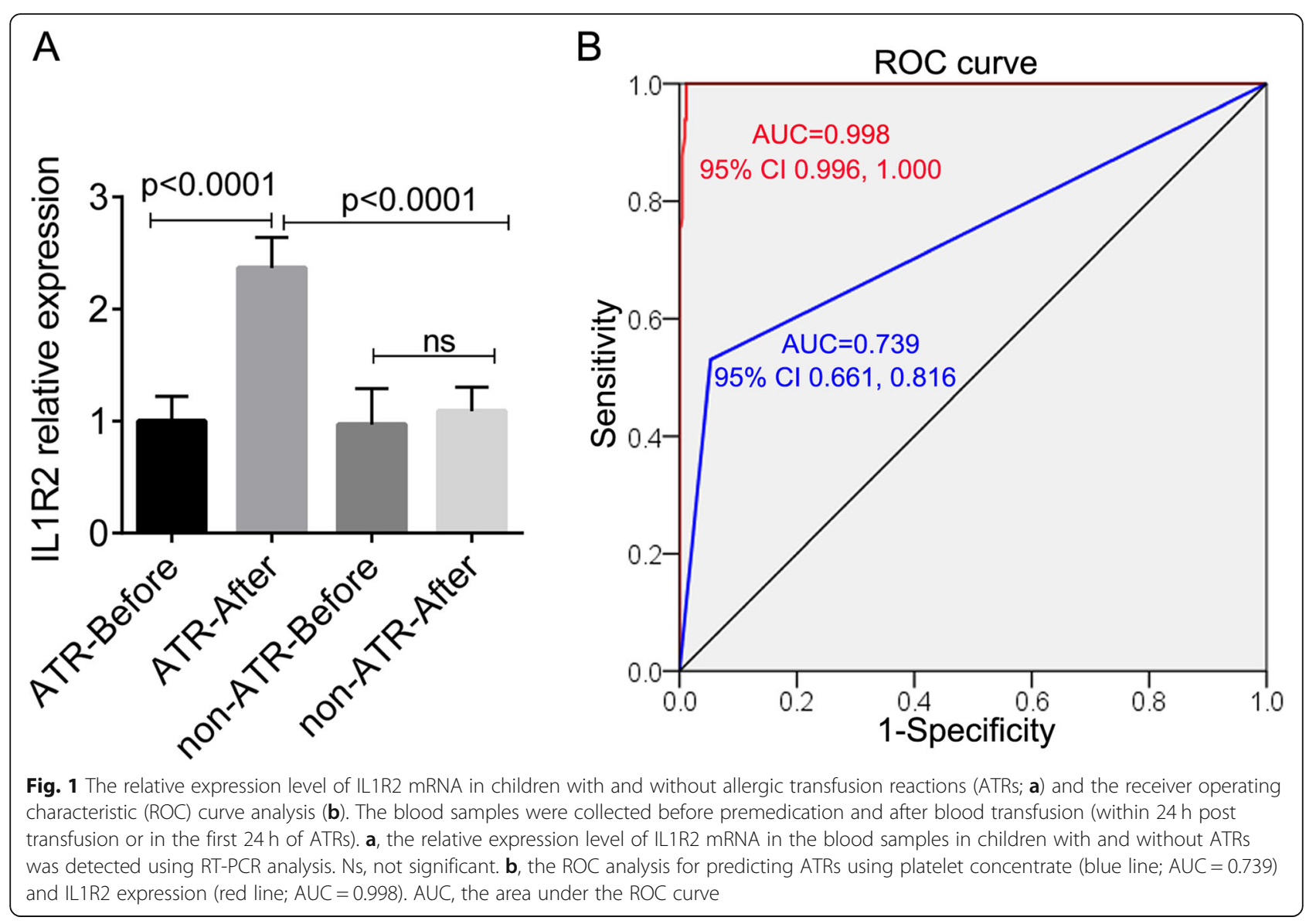

antigen (HLA) antibodies, and ATRs were related to the deficiency of antibodies including IgA, IgG, and IgE [17]. However, the associations are not common now because of the use of washed and filtered RBC, and irradiationtreated platelets $[17,18]$. A previous report has shown that HLA-DR mediated the production of IL- $1 \beta$ in human monocytes [19]. Also, there is a contrary regulation that IL-1 $\beta$ upregulated HLA-G expression in immune cells [20]. The activation of IL-1 $\beta$-dependent intracellular signaling plays crucial role in immune diseases and responses [7, 21, 22]. However, there is less information on the association of IL1R2 with IL- $1 \beta$-dependent intracellular signaling during the pathogenesis of diseases.
The increased expression of IL1R2 has been associated with poor prognosis and metastasis of several malignancies $[23,24]$. The ratio of IL-1 $\beta /$ IL1R2 positively correlated with the production of interferon $\gamma$, and negatively correlated with TNF- $\alpha$ production in women with invasive ductal mammary adenocarcinomas [23]. These results showed that the dynamic equilibrium between IL1-dependent intracellular signaling and IL1R2 was associated with the progression of human diseases.

IL-1-dependent intracellular signaling attributes to the pathogenesis of many diseases including arteriosclerosis [8], rheumatoid arthritis [25], type 2 diabetes [25, 26], and pustular psoriasis [27]. The inhibition of IL-1,

Table $\mathbf{2}$ Logistics regression analysis of the risk factors for allergic transfusion reactions

\begin{tabular}{llllllll}
\hline Variable & $\beta$ & $\begin{array}{l}\text { Univariate } \\
\text { OR }(95 \% \mathrm{Cl})\end{array}$ & $P$ & $\beta$ & $\begin{array}{l}\text { Multivariate } \\
\text { OR }(95 \% \mathrm{Cl})\end{array}$ & $P$ \\
\hline Sex & -0.342 & $0.710(0.421,1.198)$ & 0.200 & & & & \\
PC & 3.004 & $20.175(10.635,38.275)$ & $<0.0001$ & 3.476 & $32.318(3.555,293.782)$ & 0.002 \\
Number of transfusion & 0.499 & $1.648(1.426,1.904)$ & $<0.0001$ & 0.152 & $1.164(0.646,2.099)$ & 0.613 \\
Age & 0.073 & $1.076(1.016,1.139)$ & 0.013 & 0.085 & $1.089(0.877,1.352)$ & 0.440 \\
IL1R2 expression & 8.255 & $5.574 \times 10^{3}\left(2.569 \times 10^{2}, 5.756 \times 10^{4}\right)$ & $<0.0001$ & 7.187 & $1.322 \times 10^{3}\left(1.171 \times 10^{2}, 1.494 \times 10^{4}\right)$ & $<0.0001$ \\
\hline
\end{tabular}

$O R$ odds ratio, $\mathrm{Cl}$ confidence interval, $P C$ platelet concentrate 
however, showed an impressive effect on treating these diseases $[28,29]$. Upon the activation of IL, IL1R2 competes with IL1R1 for IL-1 and forms an IL1R2/IL-1RAP complex, and therefore suppressing IL-1-dependent intracellular signaling [7]. In in vitro and in vivo experiments, expression of IL1R2 has been identified as an anti-inflammatory mediator with therapeutic value in several diseases including arteriosclerosis $[7,8]$ and arthritis [30,31]. According to the above studies, we speculated that the significant upregulation of IL1R2 in children with ATRs might act on suppressing IL-1 signaling and reducing the inflammatory responses in patients.

\section{Conclusions}

We concluded that the expression of IL1R2 and platelet transfusion could be used as independent factors for ATRs in children that received blood transfusions. The high expression of IL1R2 in children with ATRs might be an indicator of suppressing IL-1-mediated inflammations.

\section{Supplementary information}

Supplementary information accompanies this paper at https://doi.org/10. 1186/s13052-020-00869-6.

Additional file 1: Table S1. Logistics regression analysis of the risk factors for allergic transfusion reactions without febrile non-hemolytic transfusion reactions.

\section{Acknowledgements}

Not Applicable.

\section{Authors' contributions}

Conception and design of the research: Yudong Dai and Xiaowei Wang. Acquisition, analysis and interpretation of data: Li Feng, Meng Li, and Ting Li. Statistical analysis: Wenjing Hu and Xiaowei Wang. Drafting the manuscript: Wenjing Hu and Li Feng. Obtaining funding: Yudong Dai and Xiaowei Wang; Manuscript revision for important intellectual content: Yudong Dai and Xiaowei Wang. All authors have read and approved the manuscript.

\section{Funding}

This study is supported by the Health Science and Technology Development Special Foundation of Nanjing (YKK18141), Nanjing Medical University Science and Technology Foundation (2017NJMUZD057), Health Science and Technology Development Special Foundation of Nanjing (YKK17203).

\section{Availability of data and materials}

The data supporting the conclusions of this article are included within the article. The original data is available from author (Xiaowei Wang) with reasonable request.

\section{Ethics approval and consent to participate}

An ethical approval was obtained from the Ethics Committees of the Children's Hospital of Nanjing Medical University, Nanjing, China, and human experiments were performed strictly according to the revised (2013) Helsinki Declaration of 1975. Written informed consents were obtained from the guardians of all patients before sample collection.

\section{Consent for publication}

Consents for publication were obtained from guardians of children with allergic transfusion reactions.

\section{Competing interests}

The authors declare that they have no competing interests.

\section{Author details}

${ }^{1}$ Department of Blood Transfusion, Women's Hospital of Nanjing Medical University, Nanjing Matcrnity and Child Health Care Hospital, Nanjing 210004, China. 'Department of Blood Transfusion, Children's Hospital of Nanjing Medical University, 72 Guangzhou Avenue, Nanjing, Jiangsu 210008, P.R. China. ${ }^{3}$ Nanjing Red Cross Blood Center, \#3 Zizhulin, Nanjing 210003, China.

Received: 8 April 2020 Accepted: 16 July 2020

Published online: 29 July 2020

\section{References}

1. Hirayama F. Current understanding of allergic transfusion reactions: incidence, pathogenesis, laboratory tests, prevention and treatment. $\mathrm{Br}$ J Haematol. 2013;160:434-44.

2. Heddle N, Klama L, Griffith L, Roberts R, Shukla G, Kelton J. A prospective study to identify the risk factors associated with acute reactions to platelet and red cell transfusions. Transfusion. 1993;33:794-7.

3. Bussolino F, Breviario F, Tetta C, Aglietta M, Mantovani A, Dejana E. Interleukin 1 stimulates platelet-activating factor production in cultured human endothelial cells. J Clin Invest. 1986;77:2027-33.

4. Bussolino F, Camussi G, Baglioni C. Synthesis and release of plateletactivating factor by human vascular endothelial cells treated with tumor necrosis factor or interleukin 1 alpha. J Biol Chem. 1988;263:11856-61.

5. Poubelle P, Gingras D, Demers C, Dubois C, Harbour D, Grassi J, RolaPleszczynski M. Platelet-activating factor (PAF-acether) enhances the concomitant production of tumour necrosis factor-alpha and interleukin-1 by subsets of human monocytes. Immunology. 1991;72:181.

6. Šerbić-Nonković O, Kuzmanović M, Životić M, Žunić S, Jovičić-Gojkov D, Vujić D. Independent role of interleukin-6 and interleukin-8 in the etiology of transfusion reactions to platelet concentrates in children. Vojnosanit Pregl. 2018;75:390-7.

7. Peters VA, Joesting JJ, Freund GG. IL-1 receptor 2 (IL-1R2) and its role in immune regulation. Brain Behav Immun. 2013;32:1-8.

8. Ahmadi F, Esmaeilzadeh A. IL-1R2: a novel approach for gene therapy in atherosclerosis. Hypothesis J. 2016;14:e1.

9. Schlüter T, Schelmbauer C, Karram K, Mufazalov IA. Regulation of IL-1 signaling by the decoy receptor IL-1R2. J Mol Med. 2018;96:983-92.

10. McMahan CJ, Slack JL, Mosley B, Cosman D, Lupton SD, Brunton LL, Grubin CE, Wignall JM, Jenkins $N$, Brannan Cl. A novel IL-1 receptor, cloned from B cells by mammalian expression, is expressed in many cell types. EMBO J. 1991;10:2821-32.

11. Yanagisawa R, Shimodaira S, Sakashita K, Hidaka Y, Kojima S, Nishijima F, Hidaka E, Shiohara M, Nakamura T. Factors related to allergic transfusion reactions and febrile non-haemolytic transfusion reactions in children. Vox Sang. 2016;1 10:376-84.

12. Mertes PM, Tacquard C, Andreu G, Kientz D, Gross S, Malard L, Drouet C, Carlier M, Gachet C, Sandid I. Hypersensitivity transfusion reactions to platelet concentrate: a retrospective analysis of the French hemovigilance network. Transfusion. 2019;60:507-12.

13. Ikebe E, Matsuoka S, Tanaka A, Yonemura Y, Fujii Y, Ohsaka A, Okazaki H, Kitazawa J, Ohtani S, Nakayama T. Reduction in adverse transfusion reactions with increased use of washed platelet concentrates in Japan-a retrospective multicenter study. Transfus Apher Sci. 2019;58:162-8.

14. Tobian AA, Savage WJ, Tisch DJ, Thoman S, King KE, Ness PM. Prevention of allergic transfusion reactions to platelets and red blood cells through plasma reduction. Transfusion. 2011;51:1676-83.

15. Chang C-C, Lee T-C, Su M-J, Lin H-C, Cheng F-Y, Chen $Y-T$, Yen T-H, Chu F-Y. Transfusion-associated adverse reactions (TAARs) and cytokine accumulations in the stored blood components: the impact of prestorage versus poststorage leukoreduction. Oncotarget. 2018;9:4385.

16. Lin JS, Tzeng CH, Hao TC, Hu HY, Ho YT, Lyou JY, Liu J, Ho CH, Yung CH. Cytokine release in febrile non-haemolytic red cell transfusion reactions. Vox Sang. 2002:82:156-60.

17. Robitaille N, Delage G, Long A, Thibault L, Robillard P. Allergic transfusion reactions from blood components donated by IgA-deficient donors with and without anti-lgA: a comparative retrospective study. Vox Sang. 2010;99: 136-41. 
18. Mourad Z, Hassab H, Younan D, Abdo A. Human leucocyte antigen alloimmunisation in repeatedly transfused thalassemic Egyptian children and its relation to febrile non-haemolytic transfusion reactions. Transfus Med. 2015;25:380-4. https://doi.org/10.1111/tme.12261.

19. Palkama T, Hurme M. Signal transduction mechanisms of HLA-DR-mediated interleukin-1 beta production in human monocytes. Role of protein kinase C and tyrosine kinase activation. Hum Immunol. 1993;36:259-67.

20. Ullah M, Azazzen D, Kaci R, Benabbou N, Pujade Lauraine E, Pocard M, Mirshahi M. High expression of HLA-G in ovarian Carcinomatosis: the role of interleukin-1 $\beta$. Neoplasia. 2019;21:331-42.

21. Xu S-L, Lin Y, Liu W, Zhu X-Z, Liu D, Tong M-L, Liu L-L, Lin L-R. The P2X7 receptor mediates NLRP3-dependent IL-1 $\beta$ secretion and promotes phagocytosis in the macrophage response to Treponema pallidum. Int Immunopharmacol. 2020;82:106344.

22. Cui Z-W, Kong L-L, Zhao F, Tan A-P, Deng Y-T, Jiang L. Bacteria-induced IL$1 \beta$ and its receptors in snakehead (Channa argus): evidence for their involvement in antibacterial innate immunity. Fish Shellfish Immunol. 2020; 100:309-16.

23. Autenshlyus A, Arkhipov S, Mikhailova E, Marinkin I, Arkhipova V, Varaksin N. The Relationship Between Cytokine Production, CSF2RA, and IL1R2 Expression in Mammary Adenocarcinoma, Tumor Histopathological Parameters, and Lymph Node Metastasis. Technol Cancer Res Treat. 2019:18. https://doi.org/10.1177/1533033819883626.

24. Zhang L, Qiang J, Yang X. IL1R2 Blockade Suppresses Breast Tumorigenesis and Progression by Impairing USP15-Dependent BMI1 Stability. Adv Sci (Weinh). 2019;7:1901728. https://doi.org/10.1002/advs.201901728.

25. Ruscitti P, Ursini F, Cipriani P, Greco M, Alvaro S, Vasiliki L, Di Benedetto P, Carubbi F, Berardicurti O, Gulletta E. IL-1 inhibition improves insulin resistance and adipokines in rheumatoid arthritis patients with comorbid type 2 diabetes: an observational study. Medicine. 2019;98:e14587.

26. Banerjee M, Saxena M. Interleukin-1 (IL-1) family of cytokines: role in type 2 diabetes. Clin Chim Acta. 2012;413:1163-70.

27. Johnston A, Xing X, Wolterink L, Barnes DH, Yin Z, Reingold L, Kahlenberg JM, Harms PW, Gudjonsson JE. IL-1 and IL-36 are dominant cytokines in generalized pustular psoriasis. J Allergy Clin Immunol. 2017;140:109-20.

28. Dusser P, Koné-Paut I. IL-1 inhibition may have an important role in treating refractory Kawasaki disease. Front Pharmacol. 2017:8:163.

29. Ruscitti P, Cipriani P, Liakouli V, Carubbi F, Berardicurti O, Di Benedetto P, Ciccia F, Guggino G, Alvaro S, Triolo G. The emerging role of IL-1 inhibition in patients affected by rheumatoid arthritis and diabetes. Rev Recent Clin Trials. 2018;13:210-4.

30. Martin P, Palmer G, Rodriguez E, Seemayer CA, Palomo J, Talabot-Ayer D, Gabay C. Deficiency in IL-1 receptor type 2 aggravates K/BxN serum transfer-induced arthritis in mice but has no impact on systemic inflammatory responses. J Immunol. 2017;198:2916-26.

31. Bessis N, Guéry L, Mantovani A, Vecchi A, Sims JE, Fradelizi D, Boissier MC The type II decoy receptor of IL-1 inhibits murine collagen-induced arthritis. Eur J Immunol. 2000;30:867-75.

\section{Publisher's Note}

Springer Nature remains neutral with regard to jurisdictional claims in published maps and institutional affiliations.

Ready to submit your research? Choose BMC and benefit from:
- fast, convenient online submission
- thorough peer review by experienced researchers in your field
- rapid publication on acceptance
- support for research data, including large and complex data types
- gold Open Access which fosters wider collaboration and increased citations
- maximum visibility for your research: over 100M website views per year
At BMC, research is always in progress.
Learn more biomedcentral.com/submissions

